И, сифилитической инфекции в России (сообщение I)

(С) Чеботарев В.В.', Земцов М.А. ${ }^{2}$, Одинец А.В. ${ }^{1}$, Чеботарева Н.В. ${ }^{3}$

\footnotetext{
1 ФГОУ В0 «Ставропольский государственный медицинский университет» Минздрава России

355017, Россия, г. Ставрополь, ул. Мира, д. 310

2 ГБУЗ Ставропольского края «Краевой клинический кожно-венерологический диспансер»

355021, Россия, г. Ставрополь, ул. Достоевского, д. 52

${ }^{3}$ ФГАОУ ВО «Российский университет дружбы народов»

117198, Россия, г. Москва, ул. Миклухо-Маклая, д. 6
}

В историческом аспекте изложены экспериментальные исследования, проводимые отечественными и зарубежными специалистами по изучению T. pallidum. Установлены инкубационный период, ее продвижение по лимфратическим и кровеносным путям. Изучены клинические проявления сифилиса у обезьян, кроликов, соответствующие стадийным проявлениям у больного сифрилисом; характер иммунитета, понятия о супер- и реинфрекции, скрытых формах сифилиса, генерализации инфекции с поражением нервной, сердечно-сосудистой системы и висцеральных органов. Освещены препараты лечения больных сифрилисом в допенициллиновый период.

Ключевые слова: сифилис, клиническое течение, экспериментальные исследования, лечение.

Конфрликт интересов: авторы данной статьи подтвердили отсутствие конфрликта интересов, о котором необходимо сообщить.

Источник фринансирования: поисково-аналитическая работа проведена на личные средства авторского коллектива.

Для цитирования: Чеботарев В.В., Земцов М.А., Одинец А.В., Чеботарева Н.В. Исторические аспекты этиопатогенеза и лечения сифилитической инфекции в России (сообщение I). Вестник дерматологии и венерологии. 2020;96(6):07-13. doi: https://doi.org/10.25208/vdv1178 


\title{
- istorical aspects of etiopathogenesis and treatment of syphilitic infection in Russia (report I)
}

\author{
(C) Vyacheslav V. Chebotarev ${ }^{1}$, Mikhail A. Zemtsov² ${ }^{2}$, Alexey V. Odinets ${ }^{1}$, Natalia V. Chebotareva ${ }^{3}$
}

\author{
${ }^{1}$ Stavropol State Medical University of the Ministry of Healthcare of the Russian Federation \\ Mira str., 310, Stavropol, 355017, Russia \\ ${ }^{2}$ Stavropol regional clinical skin and Venereological dispensary \\ Dostoevsky str., 52, Stavropol, 355021, Russia \\ ${ }^{3}$ Peoples' friendship University of Russia \\ Miklukho-Maklaya str., 6, Moscow, 117198, Russia
}

In the historical aspect, experimental studies conducted by domestic and foreign researchers on the study of $T$. pallidum are presented. The incubation period and its progress through the lymphatic and circulatory pathways are established. We studied the clinical manifestations of syphilis in monkeys and rabbits corresponding to the stage manifestation in a patient with syphilis. The nature of immunity, concepts of super-and reinfection, hidden forms of syphilis, generalization of infection with damage to the nervous, cardiovascular system and visceral organs. Drugs for the treatment of patients with syphilis in the prepenicillin period are highlighted.

Keywords: syphilis, clinical course, experimental studies, treatment.

Conflict of interest: the authors of this article have declared the absence of conflicts of interest, which shall be reported if any.

Source of funding: search and analytic were financed by the team of authors' personal funds.

For citation: Chebotarev VV, Zemtsov MA, Odinets AV, Chebotareva NV. Historical aspects of etiopathogenesis and treatment of syphilitic infection in Russia (report I). Vestnik Dermatologii i Venerologii. 2020;96(6):07-13.

doi: https://doi.org/10.25208/vdv1178 
Анализ исторических аспектов лечения больных сифилисом необходим, чтобы вспомнить и не забывать, как отечественные и зарубежные ученые внедряли новые препараты в лечение больных сифилисом, проводили экспериментальные исследования, изучая их эффрективность на обезьянах, кроликах, а затем разрабатывали методики терапии. Новое поколение дерматовенерологов должно оценить этот опыт и взять из него лучшее.

С момента появления эпидемии сифилиса в Европе в XV в. инфекция привлекла внимание в связи с тем, что протекала коварно и затрагивала все слои населения. В 1644 г. в России издается специальное уложение о подготовке по лечению сифилиса. В 1750 г. в Петербурге создается лечебно-исправительное заведение для заключения женщин развратного поведения под названием «Калининский дом» с госпиталем при нем.

В 1897 г. врач А. Сабинин писал, что «сифилис у нас в России по силе распространения составляет поистине народное бедствие». В связи с этим в 1897 г. проведен Первый Всероссийский съезд по выработке мер борьбы с этой инфекцией. Было принято решение о подготовке специальных кадров для лечения этой болезни, о госпитализации больных, бесплатном их лечении, регистрации, санитарном просвещении и др. [1]. Реализация решений шла сложно, а наступившая в 1914 г. Первая мировая война повлекла за собой значительный рост заболеваемости сифилисом.

В начале 1917 г. состоялся Пироговский съезд, одним из обсуждаемых вопросов которого было подведение итогов последствий войны и предохранение страны от занесения из армии венерических заболеваний. В период Гражданской войны было не до борьбы с венерическими болезнями. Однако проблема стояла остро, и в 1923 г. в Москве был созван Всероссийский венерологический съезд, назвавший сифилис социально значимым заболеванием, были определены задачи борьбы с инфекцией, стали открывать кожно-венерологические диспансеры [1].

Понимая тяжесть течения сифилитической инфекции у взрослых, передачу сифилиса потомству, необходимо было прежде получить экспериментальную модель инфекции, а затем изучить возможные препараты для лечения. В связи с этим еще до открытия бледной трепонемы начали проводить инфицирование обезьян (шимпанзе).

И.И. Мечников и Е. Ру [2] привили серозное отделяемое твердого шанкра больного сифилисом (нелеченого) в крайнюю плоть клитора шимпанзе. Через 26 дней появился твердый шанкр, а на 56-й день на коже спины, живота, бедер - рассеянные папулы. Установлено сходство клинических проявлений у шимпанзе с первичным и вторичным сифилисом человека.

И.И. Мечников [2] и Д.К. Заболотный [3] определили инкубационный период: у обезьян твердый шанкр появлялся через 10-45 дней после инфицирования, у кроликов - через 17-25 дней.

Д.К. Заболотный [3] произвел заражение 50 бабуинов материалом, взятым от человека, больного сифрллисом, с последующими пассажами от обезьяны к обезьяне. Он наблюдал у ряда животных проявления вторичного сифилиса (папулы, реже розеолы), рассматривая сифилис как генерализованную инфекцию. Описал поражение лимфатических узлов (регионарные адениты, полиадениты) с нахождением в них спирохет.
При гистологическом исследовании установил сходство специфических поражений у человека и обезьян. Описал первичный кератит с наличием типичных трепонем.

Открытие Ф. Шаудином и Е. Гоффрманом [4] возбудителя сифилиса - бледной трепонемы (T. pallidum) дало новый толчок экспериментальным исследованиям.

А. А. Ценовскому [5] удалось привить низшим обезьянам содержимое гуммозного инфилььтрата (вне стадии распада) и инфицировать их. Обезьяны были идеальными животными для экспериментальных исследований, изучения сифилитической инфекции. Ю.А. Финкельштейн [6] доказал, что у кроликов можно получить все стадии сифилиса, которые клинически, гистологически и бактериологически схожи с сифилисом человека.

Необходимо было отработать методики и места инфрицирования экспериментальных животных. Отечественные и зарубежные исследователи пришли к заключению, что более оправдан способ прививки у кроликов в ткань яичек или кожу мошонки $[7,8]$. Имело важное значение понимание излюбленной локализации для размножения возбудителя. Известно, что T. pallidum является анаэробом, в связи с чем кровь не должна быть подходящим местом для ее размножения. Действительно, она содержит 20\% кислорода в артериальной крови и до $12 \%$ - в венозной. В лимфе (лимфатических узлах) имеется всего около 0,1\% кислорода. Можно было предположить, что это идеальная зона пребывания трепонемы [9].

E. Zimmermann [10] заразил группу кроликов внутривенно и путем переливания крови установил, что от 24 ч до 31 дня кровь у кроликов не является заразной. Уже через несколько часов после внутривенного введения спирохеты начинают исчезать из нее. Автор предположил, что после заражения в крови часть спирохет циркулирует короткое время, а затем попадает лимфатическим путем в регионарные лимфатические узлы. Здесь спирохеты размножаются, а затем вновь попадают в кровь и там же в большей части обезвреживаются. В дальнейшем организму не удается их обезвредить, и наступает генерализация инфекции [10].

Важным открытием, полученным в экспериментальных исследованиях, было доказательство заразительности лимфатических узлов. W. Brown и L. Pearse [11] установили, что распространение спирохет происходит по лимфатическим узлам. После заражения подкожно в мошонку кусочком твердого шанкра кроликов через 48 ч они их удалили и заразили других кроликов. Прививали кроликам материал лимфатических узлов от нелеченых больных сифилисом с выраженными клиническими проявлениями. У кроликов возникали твердые шанкры в 20-30\% случаев, а бессимптомная инфекция была у остальных. W. Brown, L. Pearse [11] первые доказали наличие латентного сифилиса нервной системы у кроликов при прививке спинномозговой жидкости от больного сифилисом.

П. С. Григорьев [12] получил бессимптомный сифилис при инокуляции трепонемы в переднюю камеру глаза самки кролика. Самка родила трех сифилитических детенышей с кератитами. Автор доказал возможность врожденного сифилиса при бессимптомной инфекции. Он же установил наличие бледных трепонем в стенках аорты зараженного сифилисом кролика.

Бессимптомное течение инфекции заинтересовало исследователей. Было установлено, что если приготовить 
взвесь спирохет, содержащих 10 особей в поле зрения микроскопа, развести ее в 100 раз и ввести 0,1 мл, то у 1/3 зараженных кроликов инфекция протекает бессимптомно [8]. Установлено количество спирохет, необходимое для заражения.

Ю.А. Финкельштейн [9] описал второй в мировой литературе случай сифилиса центральной нервной системы у кролика.

Весьма интересны экспериментальные исследования, касающиеся иммунитета у больных сифилисом. А. Нейссер [13] в опытах на обезьянах продемонстрировал возможность повторного заражения, показав, что истинного иммунитета при заражении сифилисом не существует. Экспериментальные исследования на кроликах доказали возможность не только реинфекции, но и таких понятий, как суперинфекция, противошанкерный иммунитет, ресуперинфекция [14, 15]. Установлено, что и в эксперименте, и в клинике у зараженных сифилисом возникает инфекционный иммунитет, сохраняющийся при наличии бледной трепонемы и исчезающий при излеченном сифилисе [16, 17].

Проведенные экспериментальные исследования подготовили фрундамент для дальнейшего изучения течения сифилитической инфекции, эфффективности используемых препаратов, механизма их действия, а также возникающих побочных явлений. Первым препаратом для лечения больных сифилисом была ртуть, которой лечили больных на протяжении более чем 400 лет.

Ртуть. Препараты ртути использовали в лечении больных сифилисом в виде втирания 33 или 50\%-й мази из пергаментных пакетиков. Проводили внутримышечные (в/м) инъекции: салициловая ртуть 54\% в виде взвеси порошка в персиковом масле. Соли ртути предварительно подогревали, взбалтывали и вводили двухмоментным способом: создавалось депо ртути, которая постепенно всасывалась, обеспечивая максимально переносимую организмом концентрацию. Растворимые препараты ртути вводили внутривенно (в/в): цианистая ртуть $1 \%$, что создавало высокие, но кратковременные концентрации в крови [18].

Среди побочных явлений отмечали интоксикации. Ртуть обнаруживали практически во всех органах и тканях. Элиминация ртути шла через почки, кал, слюну, желчь, слезы, пот. Но во внутренних органах ее находили спустя несколько месяцев и даже до десяти лет. Из побочных явлений отмечены ртутные стоматиты, гингивиты, обнажались стенки зубов, выпадали зубы, десны кровоточили. По краю языка и щек на фоне отечной слизистой возникали отпечатки зубов, болезненные язвы, изъязвления, гнойный налет. Из общих симптомов при лечении ртутью отмечали ртутную дрожь, острое воспаление нервов, слабость, похудение, бледность кожи, ртутный грипп [19].

Было показано, что если в разведенную в 5-40 мг на 1 л сулему поместить трепонемы, то в первых трех разведениях имеет место их рост. Это опровергало прямое специфическое ее действие на возбудителя: механизм действия ртути опосредован через организм [20].

Вторым препаратом в лечении сифилиса были соединения йода. Препараты применяли сочетанно, главным образом при поздних формах сифилиса. Йодистые препараты хорошо действовали на проявления третичного сифилиса кожи, слизистых оболочек, внутренних органов, центральной нервной системы и сердечно-сосудистой. Научные данные не подтвердили прямого действия йода на T. pallidum. Установлено, что йод оказывал рассасывающее действие на инфильтраты, откладываясь в пораженных тканях. Йод также назначали после завершения курса терапии ртутью, чтобы вывести указанные металлы из организма [21].

Третьим препаратом в лечении сифилиса стал мышьяк. Первое соединение мышьяка - атоксил было открыто A. Bessemans в 1863 г., а применил его в практике Блюменталь [21] в 1902 г. В дальнейшем P. Ehrlich [22] испытал действие мышьяка в эксперименте, заражая животных T. pallidum. Однако при низких дозах возникали рецидивы инфекции, а при высоких выраженный токсический эфрфект, заканчивающийся в ряде случаев гибелью животных. Кроме того, атоксил не убивал возбудителя in vitro, и P. Ehrlich [22] не стал его изучать.

В дальнейшем P. Ehrlich [23] установил химическую структуру атоксила и совместно со своим сотрудником S. Hata (1910) поставил задачу разработать препарат, у которого лечебная доза в 10-20 раз была меньше токсической, и создал ряд мышьяковистых препаратов.

Первый из них (препарат «606») получил название «сальварсан» и был передан в психиатрическую больницу для лечения прогрессивного паралича. Было много дискуссий об эффрективности сальварсана, его побочных действиях (даже со смертельным исходом), токсичности, нестойкости, плохой растворимости, что заставило P. Ehrlich [23] продолжать свои изыскания. Он остановился на опыте «914», названном «неосальварсан», содержащем меньше мышьяка (21-22\%) по сравнению с сальварсаном (31\%) и менее токсичном. Неосальварсан был признан в мире как эфффективный и отличающийся простотой введения (в/в или в/М). Побочных эффектов при назначении неосальварсана было гораздо меньше в сравнении с сальварсаном.

В СССР химиками завода им. Карпова был разработан отечественный препарат - новарсенол, идентичный по фризико-химическим и терапевтическим свойствам неосальварсану и соответствующий требованиям гигиенического комитета Лиги Наций. В дальнейшем разработан осарсол - отечественный препарат, содержащий 27,2\% мышьяка. Выпускался в виде порошка и таблеток по 0,25 мг. В 1935 г. в СССР разработан миарсенол для внутримышечного введения (содержание мышьяка от 18 до 19,5\%), впервые изготовленный электрохимическим путем, гарантирующим абсолютное отсутствие в препарате побочных ядовитых примесей, содержащих серу [24].

При назначении миарсенола регресс высыпаний происходил медленнее, чем при в/в введении новарсенола, но было меньше и побочных эффектов. Препарат назначали при непереносимости других мышьяковых соединений, в детской практике, у больных с сердечно-сосудистой, патологией, при заключительных курсах лечения предыдущими препаратами мышьяка.

Четвертым препаратом стал висмут. Висмут, как и ртуть, принадлежит группе тяжелых металлов. Оказалось, что различные препараты висмута при одинаковом количестве содержащегося металла отличались и по терапевтическому, и по токсикологическому действию [25]. Более токсичны были растворимые в воде препараты. Они действовали быстрее, 
но и элиминировали быстрее, что снижало их эфрфективность. Нерастворимые препараты висмута в масле медленно элиминировали, хорошо переносились, но их действие на серореакции оказалось слабым.

М.А. Розентул и С. Астрова [26] в качестве проводника обогатили масло лецитином и создали новый препарат - сольбис, который Ученым советом Наркомздрава СССР был разрешен к выпуску (его вводили в/М). Эксперименты на кроликах и в клинике (519 больных сифилисом) показали, что препарат высокоэффективен. В дальнейшем в СССР были изготовлены бийохинол и бисмоверол. Бийохинол содержал $24 \%$ висмута, 56\% йода и 20\% хинина в персиковом или миндальном масле. Препарат постепенно всасывался и медленно выделялся, сохраняя длительное терапевтическое действие и малую токсичность. Являясь анионом, висмут проникал в центральную нервную систему (ЦНС), оказывал положительное влияние при висцеральном сифилисе, быстро улучшал состояние больных, положительно влиял на эритропоэз. Являлся активным антисифилитическим препаратом для взрослых и детей. Преимущество перед бийохинолом в том, что он вводился в/м на курс 50 мл масла, а при назначении бисмоверола - 20 мл, что уменьшало число побочных действий в виде инфильтратов и создавало лучшую элиминацию висмута [26].

Необходимо помнить, что, как указанные ранее три препарата, висмут становится спирохетоцидным только в организме. На месте инъекции, подвергаясь фрерментативному действию тканевых соков, висмут распадается, поглощается лейкоцитами и через кровь попадает в различные органы, в которых образуются активные белковые соединения висмута - токсоальбумины (бисмоксилы). Висмут занимал по силе действия на T. pallidum второе место: сальварсан, висмут, ртуть. Их терапевтическая сила - 10:7:4 соответственно [24].

Осложнения висмутовых препаратов разделяли на местные и общие. Местные - результат технических введений и схожи с лечением ртутью. Среди общих осложнений отмечали эритемы, крапивницу и др., но они возникали редко и протекали легко. Обращали внимание на висмутовую кайму - аспидносерая каемка по краю десен, чаще у нижних резцов, реже на слизистой щек, губ, миндалин и твердого неба. Они не мешали лечению и чаще наблюдались при плохом уходе за полостью рта, гиповитаминозе [24].

При сохранении общих принципов лечения больных сифрилисом в описываемый период в США пропагандировали «ускоренные», «укороченные» непрерывные методы лечения.

И зарубежные, и отечественные ученые всегда подчеркивали роль организма, влияющего на результат терапии больных сифилисом. Необходимо учитывать состояние печени, почек, щитовидной железы и других органов и систем, иммунные процессы $[27,28]$.

Полагали, что при скудной сыпи иммунизирующие вещества или совершенно не вырабатываются, или вырабатываются недостаточно. В этом причина развития аортита, табеса и прогрессивного паралича [11]. В связи с этим полноценное обследование больного сифилисом, выявление сопутствующих заболеваний необходимо.

Придавали большое значение неспецифической терапии, которая оказывала стимулирующее воздействие на организм [12, 20, 21]. У больных в поздний период сифилиса неспецифическое лечение стимулировало более быстрое рассасывание клинических проявлений инфекции. Его назначали и при замедлении или отсутствии негативации серологических реакций [24].

Итак, необходимо помнить, что ни один из препаратов не обладал прямым спирохетоцидным действием. И зарубежные, и отечественные авторы подчеркивали, что лечение больного сифилисом зависит от состояния организма. Это состояние определяет также и побочные эфрфекты.

В случае недостаточного терапевтического эффректа или его отсутствия комбинировали препараты. Объективными критериями эфффективности лечения являлись регресс не только высыпаний при манифестных формах, но и лимфатических узлов, динамика реакции Вассермана и изменения цереброспинальной жидкости.

Каковы же были отдаленные результаты лечения больных сифилисом? По данным М.А. Розентула [29], среди 271 больного, закончивших лечение в московских диспансерах и наблюдавшихся в среднем около 3 лет (независимо от фрормы сифилиса), у 114 лиц, получивших все курсы терапии полноценно леченных, рецидив инфекции произошел лишь у 1 (0,9\%). Из 80 лиц, лечившихся удовлетворительно (удлинялись межкурсовые промежутки), - у 6 (7,5\%). Из общего количества 77 больных, плохо пролечившихся (недостаточное число курсов, нарушение их ритма и др.), рецидивы возникли у $39(50,7 \%)$. Таким образом, уже в те далекие времена эфрфективность лечения была велика - 99,1\%!

\section{Заключение}

Подводя итоги научных исследований отечественных сифилидологов с момента открытия T. pallidum и до пенициллиновой эры (1940г.), можно отметить, что весь период проводилась огромная экспериментальная работа (вначале на обезьянах, затем на кроликах), позволившая четко познать пути инфицирования, распространения возбудителя сифилиса, роль лимфатической системы, заразительность лимфратических узлов. Показано, что T. pallidum на первых этапах, попадая в кровь, обезвреживается и лишь в дальнейшем происходит генерализация инфекции.

В эксперименте на кроликах было доказано существование бессимптомной инфекции у 70-80\% животных после прививки им материала лимфатических узлов нелеченых кроликов с манифестными проявлениями. Заразительна и спинномозговая жидкость больных сифилисом, вызывающая у животных латентный сифилис нервной системы, а также возможность возникновения врожденного сифилиса при бессимптомной инфекции.

Были установлены отсутствие истинного иммунитета, возможность реинфекции, суперинфекции, ресуперинфекции. Эти понятия вошли в клиническую практику. Создавались схемы лечения препаратами ртути, мышьяка, йода и висмута. Показано отсутствие прямого действия указанных препаратов на T. pallidum. Подчеркивалась роль организма и неспецифической терапии, оказывающей стимулирующее влияние на организм и более быстрый регресс клинических проявлений, обеспечивающая результативность терапии больных сифилисом. О неоценимом опыте отечественных ученых необходимо помнить и использовать его. Йодид калия уже вновь фригурирует в Клинических рекомендациях «Сифилис» (2020) в подготовительном лечении больных поздним висцеральным сифилисом. 


\section{Литература/References}

1. Чеботарев В.В., Земцов М.А. История становления и развития старейшей дерматовенерологической службы в России (к 90-летию КККВД). Ставрополь: СТГМУ, 2013. [Chebotarev VV, Zemtsov MA. History of formation and development of the oldest dermatovenerological service in Russia (to the 90th anniversary of the KKKVD). Stavropol: Publishing house StSMU;2013 (In Russ.)]

2. Metchnicoff N., Ry E. Etudes experimentales surla syphilis. Ann Inst. Pasteur. 1904.18,1.

3. Заболотный Д.К. Об экспериментальном сисрилисе бабуинов (предварительное сообщение). Арх. биол. наук. 1904. Е. № 11. С. 1-2. [Zabolotny DK. About experimental baboon syphilis (preliminary report). Arch. Biol. nauk. 1904; E (11):1-2 (In Russ.)]

4. Schaudinn F., Hoffmann E. Uber Spirochaeta pallidum bei Syphilis und die Unterschiede dieser Form gegeniiber anderen Arter dieser Gattung. Berl. Klin. Wschr. 1905. N 5. P 21.

5. Ценовский А.А. Опыты прививки третичного сифилиса низшим обезьянам. 10-й съезд русских врачей в память Н.И. Пирогова в Москве в 1907 г. СПб. 1907; [Tsenovsky AA. Experiments in vaccinating tertiary syphilis to lower monkeys. 10th Congress of Russian doctors in memory of N.I. Pirogov in Moscow in 1907. St. Petersburg 1907 (In Russ.)]

6. Финкельштейн Ю.А. К вопросу об экспериментальном сифилисе кроликов. Тр. Моск. терапевт. 0-ва, осеннее полугодие. 1911 и «Русск. врач», 1912. № 21. [Finkelstein YA. To the question about the experimental syphilis of rabbits. Proc. Mosk. therapist. 0-va, autumn halfyear. 1911 and "Russk. doctor", 1912:21 (In Russ.)]

7. Шерешевский Я.Г. Экспериментальные данные по сифилису. Мед. обзор. 1909;12:42-50. [Shereshevsky YG. Experimental data on syphilis. Med. review 1909;(12):42-50 (In Russ.)]

8. Финкельштейн Ю.А. Дальнейшие наблюдения над экспериментальным сифилисом кроликов. Прак. врач. 1913;4:58-59. 70-71. [Finkelstein JA. Further observations on experimental syphilis of rabbits. Practice doctor. 1913;(4):58-59. 70-71 (In Russ.)]

9. Финкельштейн Ю.А. К патологии экспериментального сифилиса. Венерология и дерматология. 1928;11:36-38. [Finkelstein YA. The pathology of experimental syphilis of the rabbit. Venerology and dermatology. 1928;(11):36-38 (In Russ.)]

10. Zimmermann E. Areh. Hygiene. 1930; Bd 103, H. 1-3.

11. Brown W, Pearse $L$. Latent infection with the demonstrations of spirochaeta pallida in lymphoid tissues of the rabbit. Am. 0. Syph. 1921;5:1.

12. Григорьев П.С. Руководство по венерическим болезням. Москва-Ленинград: 3-е изд. гос. изд-во. 1930. [Grigoriev PS. Guide to venereal diseases. Moscow-Leningrad: third additional State publishing house. 1930 (In Russ.)]

13. Нейссер А. Экспериментальный сифилис. 1907. [Neisser А. Experimental syphilis.1907 (In Russ.)]

14. Поспелов А.И. 0 прививке сифилиса антропоидным обезьянам и об иммунитете к сифилису. «Р.ж.к.и.в.б.». 1904;8:141-156. [Pospelov Al. About vaccination of syphilis to anthropoid monkeys and about immunity to syphilis. "R.Zh.K.I.V.b.". 1904;(8):141-156 (In Russ.)]

15. Мещерский Г.И. Чему учат случаи сифилитической реинфекции. Русская клиника. 1924. С. 3. [Meshchersky Gl. What do cases of syphilitic reinfection teach. Russian clinic. 1924:3 (In Russ.)]
16. Мещерский Г.И. Реинфекция и суперинфекция. Доклад на VIII Межд. конгр., 1930; Копенгаген. [Meshchersky Gl. Reinfection and superinfection. Report for the eighth Session. kongr.; 1930; Copenhagen (In Russ.)]

17. Павлов С.Т. К вопросу об иммунобиологических реакциях при экспериментальном сифилисе кроликов. Труды военно-мед. академии PKKA. Ленинград, 1934. [Pavlov ST. On the issue of immunobiological reactions in experimental rabbit syphilis. Proceedings of the military med. Academy of the red army. Leningrad, 1934 (In Russ.)]

18. Никольский П.В. Значение работ проф. М.И. Стуковенкова в области терапии сифилиса. Медицинское обозрение. 1907:20. [Nikolsky PV. Significance of the works of prof. M.I. Stukovenkov in the field of syphilis therapy. Medical review. 1907:20 (In Russ.)]

19. Зеленев И.Ф. Лечение сифилиса глубокими впрыскиваниями желтой окиси ртути. Военно-мед. журн. 1890;1:167. [Zelenev IF. Treatment of syphilis by deep injections of yellow oxide of mercury. Military medical journal. 1890;(1):167 (In Russ.)]

20. Поспелов А.И. Лечение сифилиса подкожными впрыскиваниями сублимата: дисс. ... Москва, 1874. [Pospelov Al. Treatment of syphilis by subcutaneous injections of sublimate: Diss. M, 1874 (In Russ.)]

21. Горбовицкий С.Е. Лечение сифилиса. Руководство по дерматовенерологии. Венерические болезни. Книга 1: Медгиз, 1959;375435. [Gorbovitskii SE. The treatment of syphilis. Manual of dermatology and venereology. Venereal disease. Book 1: Medgiz; 1959;375-435 (In Russ.)]

22. Ehrlich P. Chemotherapeutische Trypanosomenstudien. Berliner.Klin. Wochensehr, 1907.

23. Ehrlich P. Экспериментальная хемотерапия болезней, обусловленных спириллами. Перевод Н.Г. Фрейберга. СПб.: Практич. медицина, 1910;84.

24. Горбовицкий С.Е. Химиотерапия и критерии излечимости сифилиса. Современное состояние проблемы и ее экспериментальное обоснование. Ленинград, 1944. [Gorbovitskii SE. Chemotherapy and criteria of curability of syphilis. Current state of the problem and its experimental justification. Leningrad, 1944 (In Russ.)]

25. Levaditi C. Le bismuth dans be traitement de la syphilis. Paris, 1924.

26. Розентул М.А. Сифилис. Обзор наиболее актуальных работ за 1935/36 г. Венерология и дерматология. 1937;479-497. [Rosentul MA. Syphilis. An overview of the most relevant works in 1935/36. Venerology and dermatology. 1937:479-497 (In Russ.)]

27. Сифилитические заболевания в повседневной практике врача / Под ред. П. Мульцера. Ленинград: гос. изд-во Москва; 1926. [Multzer P, editor. Syphilitic diseases in the daily practice of a doctor. Leningrad: state publishing house Moscow; 1926 (In Russ.)]

28. Григорьев П.С. 0 терапии сифилиса. Научная мысль. 1927:162. [Grigoriev PS. On the treatment of syphilis. Scientific thought. 1927:162 (In Russ.)]

29. Розентул М.А. Основные вопросы организации лечения сифилиса. Вестник венерологии и дерматологии. 1937;5:479-497. [Rosentul MA. Basic organization of the treatment of syphilis. Vestnik venerologii and dermatologii. 1937,(5):479-497 (In Russ.)] 


\section{Информация об авторах}

*Михаил Алексеевич Земцов - к.м.н.; адрес: Россия, 355021, г. Ставрополь, ул. Достоевского, д. 52; ORCID iD: https://orcid.org/0000-0001-9566-9775; e-mail: kkkvd@bk.ru

Вячеслав Владимирович Чеботарев — д.м.н., профеeccop; ORCID iD: https://orcid.org/0000-0002-7026-9166; e-mail: sgmukvd@mail.ru

Алексей Васильевич Одинец - к.M.H., доцент; ORCID iD: https://orcid.org/0000-0003-3257-4343; eLibrary SPIN: 7755-0484; e-mail: odinets1@yandex.ru

Наталья Вячеславовна Чеботарева — д.м.н., професcop; eLibrary SPIN: 7480-7557; e-mail: nchvg@mail.ru

\section{Information about the authors}

*Mikhail A. Zemtsov — MD, Cand. Sci. (Med.); address: 52 Dostoevsky street, 355021, Stavropol, Russia; ORCID iD: https://orcid.org/0000-0001-9566-9775; e-mail: kkkvd@bk.ru

Vyacheslav V. Chebotarev — MD, Dr. Sci. (Med.), Professor; ORCID iD: https://orcid.org/0000-0002-7026-9166; e-mail: sgmukvd@mail.ru

Alexey V. Odinets - MD, Cand. Sci. (Med.), assistant professor; ORCID iD: https://orcid.org/0000-0003-3257-4343; eLibrary SPIN: 7755-0484; e-mail: odinets1@yandex.ru

Natalia V. Chebotareva — MD, Dr. Sci. (Med.), Professor; eLibrary SPIN: 7480-7557; e-mail: nchvg@mail.ru

Статья поступила в редакцию: 09.10.2020

Принята к публикации: 04.12.2020

Дата публикации: 30.12 .2020
Submitted: 09.10 .2020

Accepted: 04.12.2020

Published: 30.12 .2020 